\title{
Preface to the first English edition
}

In 1976 when the first German manuscript of this "Introduction" was completed aroma research was described as being in a phase of rapid development. This new scientific discipline had spread, from its origin as a specialized part of food chemistry, over a broad and differentiated area between physiology of flavour sensation, aroma analysis - with a fascinating spectrum of instrumental and sensory techniques - to such practical fields as food technology and flavouring production. In the meantime this tendency has continued. In many aspects our knowledge has now reached a higher level, and we can recognize many more connections between different aroma problems...It has therefore been necessary to complement the original material by new results, and to summarize some aspects in order to give the most up-todate picture possible of our discipline.

One problem, however, remained unchanged: An introduction has to present a review of the field under discussion without going into too much detail. A detailed discussion should principally be confined to the special monographs of this series. The author had to select a few appropriate examples out of a large number of possibilities, which is really a rather difficult task. Another aspect to be considered is the necessity of demonstrating the actual facts in a readily understandable way for the non-specialist who may be entering the field for the first time. Furthermore there was a demand for a translation into the English language. In spite of a concept that the individual monographs of this series were to be written either in English or in German language we feel that some volumes should be available in both languages. Moreover, we had to consider that, in the main, activities in the flavour field have developed within English speaking countries. Consequently, most authors and experts have published their results in English.

I want to thank the Akademie-Verlag Berlin and especially lector Karl ABEL for an always good and effective collaboration. All our problems were discussed and solved in a fruitful and cooperative way stimulated by an open and friendly atmosphere. Within the Central Institute for Nutrition PotsdamRehbrücke I am indebted to. our director, Prof. H. SchmandKe, as well as to Prof. H. RutTlofF for their understanding and help. Finally I should like to thank Mrs. Edith WeISE for typing the manuscript and for assistance in the English translation.

Potsdam-Rehbrücke Manfred ROTHE 
